\title{
Nitrogen functionalized carbon nanostructures supported Pd and Au-Pd NPs as catalyst for alcohols oxidation
}

\author{
A. Villa ${ }^{\mathrm{a}}$, D. Wang ${ }^{\mathrm{b}}$, P. Spontoni ${ }^{\mathrm{a}}$, R. Arrigo ${ }^{\mathrm{b}}$, D. S. Su ${ }^{\mathrm{b}}$, L. Pratia,* \\ ${ }^{a}$ Università di Milano, Dipartimento di Chimica Inorganica Metallorganica e Analitica, I-20133Milano, Italy \\ ${ }^{b}$ Department of Inorganic Chemistry, Fritz Haber Institute of the Max Planck Society, Faradayweg 4-6, \\ D-14195 Berlin, Germany \\ "Corresponding author: e-mail Laura.Prati@ unimi.it,
}

Available online 21 February 2010

\begin{abstract}
Two different carbon nanotubes (CNTs) PR24-PS and Baytubes were functionalized by oxidation with nitric acid and further amination with gaseous $\mathrm{NH}_{3}$. Thus $\mathrm{Au}$ and Au-Pd nanoparticles were prepared by PVA/NaBH 4 system and anchored on the surface of pristine $\mathrm{CNTs}$ and $\mathrm{N}$ CNTs (Nitrogen functionalized carbon nanotubes). TEM analysis revealed that the introduction of nitrogen functionalities improves the dispersion of the metal nanoparticles on the surface of the support. This phenomena leads to an improved activity of N-CNTs based catalysts with the respect of pristine CNTs when tested in the liquid phase oxidation of alcohols.
\end{abstract}

Keywords: Carbon Nanotubes, Nitrogen functionalization, alcohol oxidation, glycerol, Palladium, Gold-Palladium

\section{Introduction}

The oxidation of alcohols to their corresponding carbonyl compounds catalyzed by supported noble metal has been recently the subject of growing interest [1-3]. Due to the high costs of the noble metal it is necessary to extend and enhance their catalytic performance by depositing them homogenously on the support in order to optimize the active surface [4]. For this purpose the choice of the support is of fundamental importance influencing also the stability of the metal nanoparticles. Recently CNTs attracted a lot of attention as support for metal nanoparticles [5-9]. In particular their morphology suggests their use as support for liquid phase reactions as benzyl alcohol oxidation [10] and cinnamaldehyde hydrogenation $[11,12]$. On the contrary to activated carbons where there are many inaccessible active sites, CNTs are advantageous substrate since most of the metal nanoparticles are expected to be exposed and accessible to reactant thus acting as effective catalysts [13]. However due to the inertness of the pristine CNTs a selective metal deposition requires activation [14]. Jiang et al., for example, observed that the introduction of nitrogen groups on the surface of CNTs drastically increase the dispersion and stability of the metal nanoparticles [15], due to the strong interaction metal-nitrogen. Metal/N-CNTs sys- tem resulted more active than metal/pristine when tested in different reactions. For example, highly dispersed metal nanoparticles immobilized on nitrogen doped CNTs showed better activity than pristine CNTs for methanol oxidation [16] and hydrogenation of cinnamaldehyde $[17,18]$ and Heck reaction of iodobenzene and styrene [19]. We recently reported the preparation of N-CNTs sample by a gas phase procedure [20]. The CNTs used (PR24-PS) are characterized by large diameter $(\sim 100 \mathrm{~nm})$ and the presence of impurities, like amorphous carbon on the surface and inhomogeneity in size [21]. N-functionalized CNTs were obtained by previous acid oxidation and further amination with gaseous $\mathrm{NH}_{3}$. XPS and TG-MS revealed that these samples mainly contain pyridinic and pyrrolic groups. In the present work we extended the functionalization method to another type of CNTs, Baytubes, with the aim to study the effect of the diameter of the tubes and the presence of impurities on the surface on the metal nanoparticles dispersion and on the catalytic activity. Baytubes, in fact, are characterized by a smaller diameter than PR24-PS $(5 \mathrm{~nm}$ instead $100 \mathrm{~nm}$ ) with a better homogeneity in size and morphology, and they exhibited only little amorphous carbon on their surface [20]. Pristine CNTs and N-CNTs were used as support for $\mathrm{Pd}$ and $\mathrm{Au}-\mathrm{Pd}$ nanoparticles prepared by colloidal method using PVA (polyvinyl alcohol) as protec- 
tive agent [22]. The catalysts were characterized by TEM in order to investigate the effect of the nitrogen functionalities on the dispersion of the metal nanoparticles. All the catalysts were tested in the liquid phase oxidation of benzyl and cinnamyl alcohol.

\section{Experimental}

\subsection{Materials}

Commercial CNTs PR24-PS-PS and Baytubes were supplied respectively from Applied Science and from Bayer. PR24-PS-PS consist of tubular fibers with an average diameter of $88 \pm 30 \mathrm{~nm}$ and a specific surface area of $43 \mathrm{~m}^{2} \mathrm{~g}^{-1}$ [21] whereas Baytubes have an average diameter of $5 \pm 2 \mathrm{~nm}$ and a specific surface area of $288 \mathrm{~m}^{2} \mathrm{~g}^{-1}$ [21]. $\mathrm{NaBH}_{4}$ (Fluka, > 96\%), polyvinylalcohol (PVA) (mw = 13,000-23,000 87-89\% hydrolysed, Aldrich), $\mathrm{NaAuCl}_{4}$ $\cdot 2 \mathrm{H}_{2} \mathrm{O}$ and $\mathrm{Na}_{2} \mathrm{PdCl}_{4} \cdot 2 \mathrm{H}_{2} \mathrm{O}$ (Aldrich, $99.99 \%$ purity) were used in these experiments. Gaseous oxygen from SIAD was $99.99 \%$ pure.

\subsection{Catalyst preparation}

\subsubsection{Monometallic catalysts}

Pd sol: solid $\mathrm{Na}_{2} \mathrm{PdCl}_{4}(0.043 \mathrm{mmol})$ and $220 \mathrm{ml}$ PVA solution $(2 \%, \mathrm{w} / \mathrm{w})(\mathrm{Pd} / \mathrm{PVA} 1: 1, \mathrm{w} / \mathrm{w})$ were added to $130 \mathrm{ml}$ of $\mathrm{H}_{2} \mathrm{O}$. After $3 \mathrm{~min}, 860 \mathrm{ml}$ of $0.1 \mathrm{M} \mathrm{NaBH}_{4}$ solution was added to the yellow-brown solution under vigorous magnetic stirring. The brown $\operatorname{Pd}(0)$ sol was immediately formed. An UV-visible spectrum of the palladium sol was recorded for ensuring the complete reduction of $\mathrm{Pd}(\mathrm{II})$. Within few minutes from their generation, the colloids (acidified at $\mathrm{pH} 2$, by sulphuric acid) were immobilized by adding the support under vigorous stirring. The amount of support was calculated in order to obtain a final metal loading of $1 \mathrm{wt} \%$ (on the basis of quantitative loading of the metal on the support). The metal loading was also confirmed by burning off the CNTs and performing ICP (Jobin Yvon JV24) analyses of the solution.

\subsubsection{Bimetallic catalysts}

Bimetallic catalysts have been prepared following the procedure reported in [22]. Solid $\mathrm{NaAuCl}_{4} * 2 \mathrm{H}_{2} \mathrm{O}$ $\left(0.072 \mathrm{mmol}\right.$ ) was dissolved in $140 \mathrm{ml}$ of water (final $10^{-4}$ M) and $0.706 \mathrm{ml}$ of PVA $(2 \%$, w/w) was added (Au/PVA $1: 1, \mathrm{w} / \mathrm{w})$. The yellow solution was stirred for $3 \mathrm{~min}$ and $2.9 \mathrm{ml}$ of $0.1 \mathrm{M} \mathrm{NaBH}{ }_{4}\left(0.285 \mathrm{~mol}, \mathrm{Au} / \mathrm{NaBH}_{4} \quad 1: 3\right.$ $\mathrm{mol} / \mathrm{mol}$ ) was added under vigorous magnetic stirring. The ruby red $\mathrm{Au}(0)$ sol was immediately formed. An UVvisible spectrum of the gold sol was recorded to check the complete $\mathrm{AuCl}^{4-}$ reduction and the formation of the plasmon peak. Within a few minutes of sol generation, the gold sol was immobilized by adding carbon nanotubes (acidified until $\mathrm{pH} 2$ by sulphuric acid) under vigorous stirring. The amount of support was calculated as having a gold loading of $0.73 \mathrm{wt} \%$. After $2 \mathrm{~h}$ the slurry was filtered, the catalyst was thoroughly washed with distilled water (neutral mother liquors). ICP analyses were performed on the filtrate using a Jobin Yvon JV24 to verify the total metal loading on carbon. The $0.73 \mathrm{wt} \% \mathrm{Au} / \mathrm{CNTs}$ prepared was then dispersed in $140 \mathrm{ml}$ of water; $\mathrm{Na}_{2} \mathrm{PdCl}_{4}(0.048 \mathrm{~mol})$ and 0.225 $\mathrm{ml}$ of PVA solution $(0.2 \%$, w/w) (Au/PVA $1: 1, \mathrm{w} / \mathrm{w})$ were added. $\mathrm{H}_{2}$ has been bubbled $(50 \mathrm{ml} / \mathrm{min})$ under atmospheric pressure and room temperature for $2 \mathrm{~h}$. After additional 18 $\mathrm{h}$, the slurry was filtered; the catalyst was thoroughly washed with distilled water. ICP analyses were performed on the filtrate using a Jobin Yvon JV24 to verify the quantitative metal loading on the support. The final total metal loading was $1 \mathrm{wt} \%$. The total metal loading and $\mathrm{Au} / \mathrm{Pd}$ ratios were also confirmed by burning off the CNTs and performing ICP (Jobin Yvon JV24) analyses of the solution.

\subsection{Catalytic test}

The reactions were carried out in a thermostatted glass reactor $(30 \mathrm{ml})$ provided with an electronically controlled magnetic stirrer connected to a large reservoir (5000 $\mathrm{ml}$ ) containing oxygen at $2 \mathrm{~atm}$. The oxygen uptake was followed by a mass flow controller connected to a PC through an A/D board, plotting a flow/time diagram. The oxidation experiments were carried out in solventless $(0.0125 \mathrm{~mol}$ substrate, Substrate $/$ Metal= $35000(\mathrm{~mol} / \mathrm{mol})$, $\left.120^{\circ} \mathrm{C}, p \mathrm{O}_{2}=1,5 \mathrm{~atm}\right)$ or in the presence of water as solvent (alcohol 0,3M, Substrate $/ \mathrm{Metal}=5000(\mathrm{~mol} / \mathrm{mol}), 60{ }^{\circ} \mathrm{C}$, $\left.p \mathrm{O}_{2}=1,5 \mathrm{~atm}\right)$. In the case of solventless reaction, periodic removal of samples from the reactor was performed, whereas in the case of water solvent, after the end of the reaction the catalyst was filtered off and the product mixture was extracted with $\mathrm{CH}_{2} \mathrm{Cl}_{2}$. Recoveries were always $98 \% \pm 3$ with this procedure. For the identification and analysis of the products a GC-MS and GC (a Dani 86.10 HT Gas Chromatograph equipped with a capillary column, BP21 30m x $0.53 \mathrm{~mm}, 0.5 \mu \mathrm{m}$ Film, made by SGE), were used by comparison of the authentic samples. For the quantification of the reactant-products the external calibration method was used.

\subsection{Catalyst Characterization}

The metal content was checked by ICP analysis of the filtrate or, alternatively, directly on the catalyst after the carbon was burned off, using a Jobin Yvon JY24 instrument. A Hitachi S-4800 SEM equipped with EDX detector for elemental analysis was used to investigate the surface morphologies of the CNTs. Morphology and microstructures of the catalysts were characterized in a Philips CM200 FEG electron microscope, operating at $200 \mathrm{kV}$ and 
a)

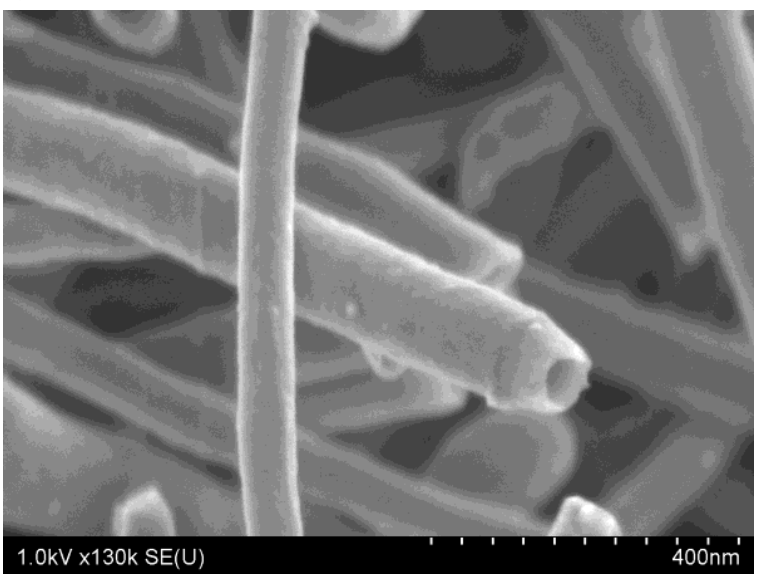

b)

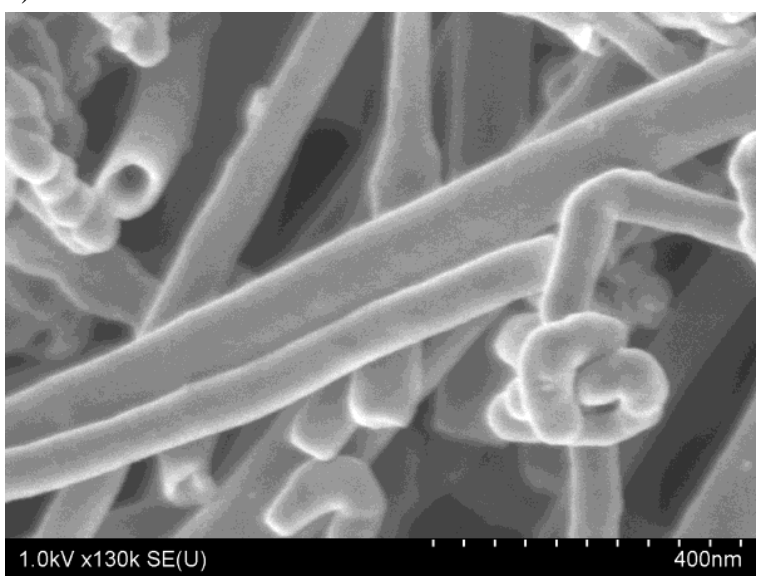

Fig. 1: SEM overview of a) pristine PR24-PS-PS and b) Nfunctionalized PR24-PS-PS

equipped with a Gatan imaging filter, GIF Tridiem. Powder samples of the catalysts were ultrasonicated in ethanol and dispersed on copper grids covered with a holey carbon film. Metal distribution analysis with a resolution of a few nanometers was performed in STEM mode in combination with energy dispersive X-ray spectroscopy (EDX) using a DX4 analyzer system (EDAX) in the same microscope.

\section{Results and discussion}

Carbon nanotubes are a promising support and an effective alternative to activated carbons for liquid phase reaction. We previously observed that Pd nanoparticles supported on CNTs (Baytubes) showed a better stability and limited leaching in comparison to activated carbon when tested in the liquid phase oxidation of benzyl alcohol [11]. However Pd/CNTs showed a lower activity than $\mathrm{Pd} / \mathrm{AC}$, according to the lower metal dispersion observed on CNTs compared to AC. This phenomenon can be addressed to the inertness of the surface of pristine CNTs. Thus in order to improve the metal-support interaction it is necessary to introduce functionalities on the surface of carbon nanotubes.
In this study, two different carbon nanotubes, Baytubes and PR24-PS were considered. Baytubes are characterized by small diameter $(5 \mathrm{~nm})$, and homogenous morphology whereas PR24-PS by larger diameter (100nm), more inhomogeneous morphology and the presence of a large amount of impurities on the surface [21]. Furthermore, the CNTs were functionalized with nitrogen groups, following a procedure that we recently report [20]. In brief, the CNTs were first oxidized with nitric acid at $100^{\circ} \mathrm{C}$ and further aminated with gaseous $\mathrm{NH}_{3}$ at $600^{\circ} \mathrm{C}$. The acid treatment introduces oxygen functionalities on the surface but at the same time removes some impurities present. SEM images of pristine and functionalized CNTs shows, in fact, that after the functionalization the impurities present on the surface of the tube (bright dots) (fig.1a) disappeared and the surface of the tube shows better homogeneity (fig. 1b). XPS revealed that these samples after amination mainly contain pyridinic and pyrrolic groups [20].

a)

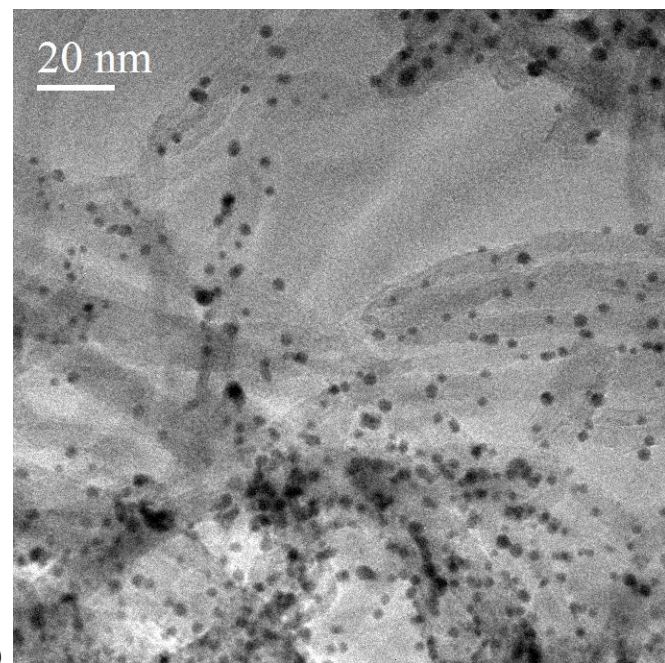

b)

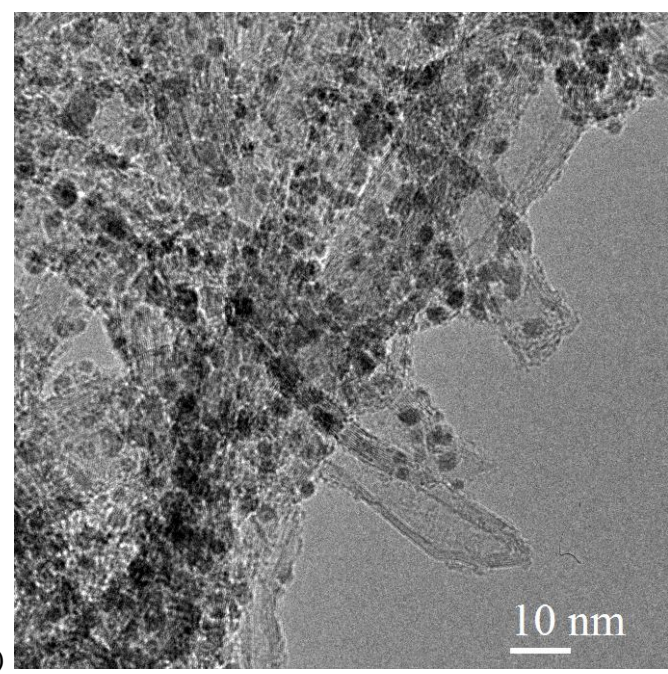

Fig. 2: The TEM overview image for (a) Pd/Baytubes and (b) $\mathrm{Pd} / \mathrm{N}-\mathrm{B}$ aytubes 

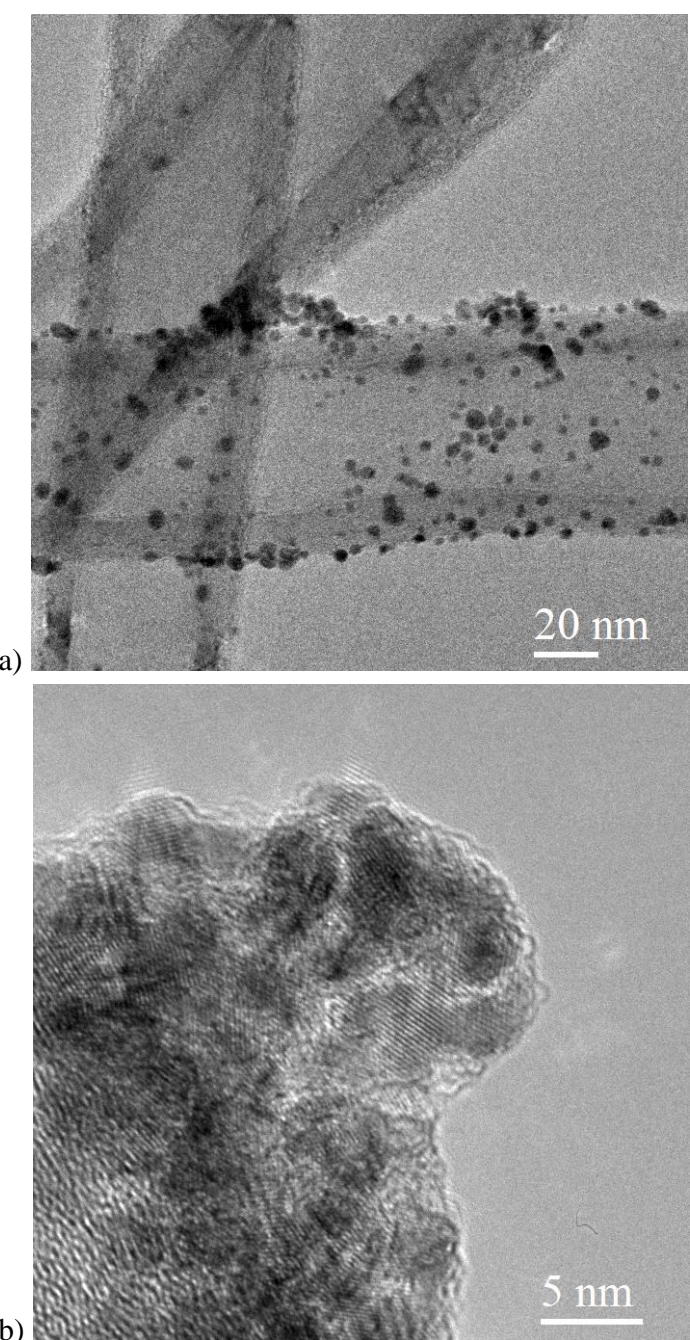

b)

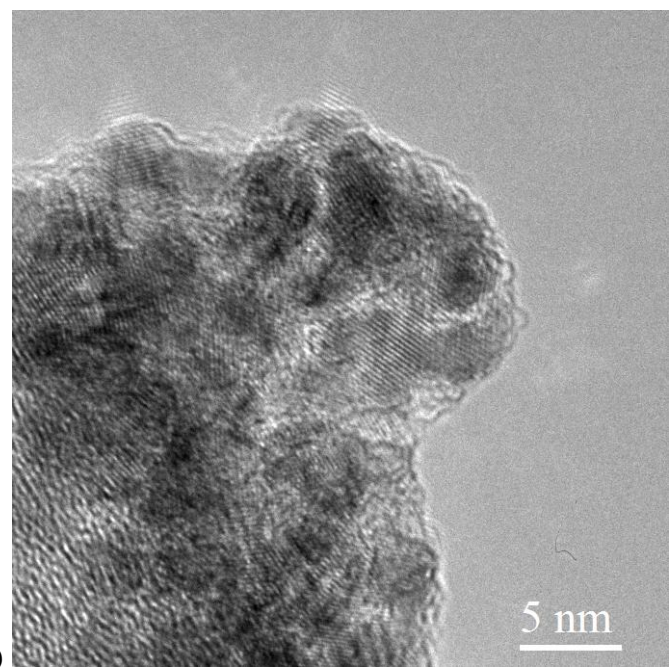

c)

Fig. 3: The TEM overview image for a) and b) Pd/PR24-PS and (c) Pd/N-PR24-PS

We synthesized $\mathrm{Pd} / \mathrm{CNTs}$ and $\mathrm{Pd} / \mathrm{N}-\mathrm{CNTs}$ via sol immobilization method $\left(\mathrm{NaBH}_{4} / \mathrm{PVA}\right)$; for $\mathrm{Au}-\mathrm{Pd}$ a two step procedure that ensures the formation of uniform alloyed $\mathrm{Pd} / \mathrm{Au}$ nanoparticles has been used [22]. The metal sols were generated in presence of a protective agent (poly
Table 1: Statistical median and standard deviation of particle size analysis for Pd and $\mathrm{Au} / \mathrm{Pd}$ catalysts.

\begin{tabular}{|c|c|c|}
\hline Catalyst & Statistical media (nm) & Standard deviation $(\sigma)$ \\
\hline Pd/Baytubes ${ }^{2}$ & 3.35 & 0.87 \\
\hline Pd/N-Baytubes & 3.34 & 0.71 \\
\hline Pd/PR24-PS & 4.28 & 1.41 \\
\hline $\mathrm{Pd} / \mathrm{N}-\mathrm{PR} 24-\mathrm{PS}$ & 3.28 & 0.93 \\
\hline $\mathrm{Au}-\mathrm{Pd} / \mathrm{Baytubes}^{2}$ & 3.53 & 0.78 \\
\hline $\mathrm{Au}-\mathrm{Pd} / \mathrm{N}$-Baytubes & 3.41 & 0.68 \\
\hline $\mathrm{Au}-\mathrm{Pd} / \mathrm{PR} 24-\mathrm{PS}$ & 4.50 & 1.46 \\
\hline $\mathrm{Au}-\mathrm{Pd} / \mathrm{N}-\mathrm{PR} 24-\mathrm{PS}$ & 3.70 & 0.93 \\
\hline
\end{tabular}

${ }^{a}$ Data from Ref. [10].

vinyl alcohol) which provides both steric as well as electrostatic stabilization of the metal nanoparticles.

All the catalysts have been fully investigated by HRTEM. For Baytubes based catalysts we can observe that Pd particles size is almost the same as for pristine and functionalized carbon nanotubes being $3.35 \mathrm{~nm}$ and $3.34 \mathrm{~nm}$ for $\mathrm{Pd} / \mathrm{Baytubes}$ and $\mathrm{Pd} / \mathrm{N}$-Baytubes. In the case of bimetallics, Au-Pd/N-Baytubes shows smaller particles than Au/Baytubes (respectively 3.41 and $3.53 \mathrm{~nm}$ ). TEM images of $\mathrm{Pd} /$ Baytubes and $\mathrm{Pd} / \mathrm{N}$-Baytubes were reported as example for Baytubes based catalysts (fig.2a and 2b). In both cases the dispersion of metal nanoparticles on the tubes is not completely homogeneous. In particular on Baytubes based catalysts several CNTs were found without metal nanoparticles, whereas in the case of N-Baytubes catalyst the empty tubes can be considered exception. The same trend was observed for $\mathrm{Au}-\mathrm{Pd} / \mathrm{Baytubes}$ and $\mathrm{Au}-\mathrm{Pd} / \mathrm{N}-$ Baytubes catalysts.

More differences were observed using pristine and functionalized PR24-PS. Pd and Au-Pd supported on pristine PR24-PS showed bigger particles than the corresponding on N-PR24-PS $(4.28 \mathrm{~nm}$ and $4.5 \mathrm{~nm}$ for Pd/PR24-PS and $\mathrm{Au}-\mathrm{Pd} / \mathrm{PR} 24-\mathrm{PS}$ whereas $3.28 \mathrm{~nm}$ and $3.70 \mathrm{~nm}$ for $\mathrm{Pd} / \mathrm{N}-\mathrm{PR} 24-\mathrm{PS}$ and $\mathrm{Au}-\mathrm{Pd} / \mathrm{N}-\mathrm{PR} 24-\mathrm{PS}$ respectively) (Table 1). Fig. 3 shows TEM images of Pd/PR24-PS (Fig. 3a and b) and Pd/N-PR24-PS (Fig. 3c) respectively. For pristine PR24-PS several tubes were found without $\mathrm{Pd}$ nanoparticles, whereas many Pd particles are observed as aggregates. Some metal nanoparticles are anchored to the amorphous carbon present on the surface of the CNTs (fig.3b). The metal-support interaction is probably promoted on the amorphous carbon full of defects. Moreover TEM observation confirmed that well dispersed nanoparticles decorate the walls of the nitrogen functionalized PR24PS quite uniformly and no empty tubes are present (fig.3c).

The catalysts were tested in the liquid phase oxidation of benzyl and cinnamyl alcohols. These reactions have been widely studies in the literature being two models of oxidation of aromatic and activated alcohols [1].

Table 2 reports the results of $\mathrm{Pd}$ and Au-Pd supported on CNTs and N-CNTs for benzyl alcohol oxidation in solventless conditions. For comparison $\mathrm{Pd}$ and $\mathrm{Au}-\mathrm{Pd}$ on $\mathrm{AC}$ have been also showed. For these experiments we used the following conditions: $0.0125 \mathrm{~mol}$ substrate, Substrate $/$ Metal $=35000(\mathrm{~mol} / \mathrm{mol}), 120^{\circ} \mathrm{C}, p \mathrm{O}_{2}=1,5 \mathrm{~atm}$. 
Table 2: Oxidation of benzyl alcohol solventless.

\begin{tabular}{|c|c|c|c|c|c|c|}
\hline \multirow[t]{2}{*}{ Catalyst } & \multirow[t]{2}{*}{$\operatorname{TOP}^{2}\left(\mathrm{~h}^{-1}\right)$} & \multicolumn{5}{|c|}{ Selectivity $^{\mathrm{b}}$} \\
\hline & & Toluene & Benzaldehyde & Benzoic acid & Benzyl benzoate & Benzene \\
\hline \multicolumn{7}{|l|}{$\mathrm{Pd}$} \\
\hline PR24-PS & 7260 & 24 & 62 & 4 & 5 & 5 \\
\hline Baytubes & 43.281 & 21 & 62 & 10 & 5 & 2 \\
\hline N-PR24-PS & 65,876 & 26 & 64 & 2 & 1 & 7 \\
\hline N-Baytubes & 50,387 & 20 & 68 & 6 & 5 & 1 \\
\hline $\mathrm{AC}$ & 47,834 & 21 & 67 & 3 & 7 & 2 \\
\hline \multicolumn{7}{|l|}{$\mathrm{Au}-\mathrm{Pd}$} \\
\hline PR24-PS & 6076 & 18 & 74 & 3 & 1 & 4 \\
\hline Baytubes & 33,580 & 13 & 75 & 7 & 4 & 1 \\
\hline N-PR24-PS & 52,638 & 15 & 75 & 4 & 4 & 1 \\
\hline $\mathrm{N}$-Baytubes & 43,479 & 11 & 76 & 7 & 5 & 1 \\
\hline $\mathrm{AC}$ & 35,426 & 12 & 76 & 6 & 3 & 3 \\
\hline
\end{tabular}

Reaction conditions: solventless; alcohol/metal: $1 / 35,000 ; \mathrm{T}=120{ }^{\circ} \mathrm{C} ; \mathrm{pO}_{2}=1.5 \mathrm{~atm}$.

${ }^{a}$ TOF calculated after $15 \mathrm{~min}$ of reaction based on the total metal loading.

${ }^{\mathrm{b}}$ Selectivity calculated at $90 \%$ conversion.

${ }^{\mathrm{c}}$ Selectivity calculated at $50 \%$ conversion.

Table 3: Oxidation of benzyl and cinnamyl alcohol in water.

\begin{tabular}{|c|c|c|c|c|}
\hline \multirow[t]{2}{*}{ Catalyst } & \multicolumn{2}{|c|}{$\underline{\text { Benzyl alcohol }}$} & \multicolumn{2}{|c|}{ Cinnamyl alcohol } \\
\hline & $\operatorname{TOF}^{2}\left(h^{-1}\right)$ & Selectivity ${ }^{\mathrm{b}}$ & $\operatorname{TOF}^{2}\left(\mathrm{~h}^{-1}\right)$ & Selectivity \\
\hline \multicolumn{5}{|l|}{ Pd } \\
\hline PR24-PS & 10 & 92 & 52 & 75 \\
\hline Baytubes & 625 & 91 & 248 & 77 \\
\hline N-PR24-PS & 836 & 93 & 494 & 76 \\
\hline N-Baytubes & 951 & 94 & 706 & 78 \\
\hline \multicolumn{5}{|l|}{$\mathrm{Au}-\mathrm{Pd}$} \\
\hline PR24-PS & 24 & 96 & 51 & 81 \\
\hline Baytubes & 747 & 97 & 300 & 82 \\
\hline N-PR24-PS & 1099 & 97 & 517 & 82 \\
\hline N-Baytubes & 1070 & 96 & 803 & 85 \\
\hline
\end{tabular}

Reaction conditions: alcohol 0.3M in water; alcohol/metal: 1/500; $\mathrm{T}=60^{\circ} \mathrm{C} ; \mathrm{pO}_{2}=1.5 \mathrm{~atm}$.

a TOF calculated after $15 \mathrm{~min}$ of reaction based on the total metal loading.

${ }^{\mathrm{b}}$ Selectivity calculated at $90 \%$ conversion.

Surprisingly in these reaction conditions Pd based catalysts show better activity than Au-Pd. This result contradicts what reported in literature, that the addition of $\mathrm{Au}$ to $\mathrm{Pd}$ increases the catalytic performances in the oxidation of alcohols [23, 24], but it has to be considered that the effect of the addition of gold normally has been studied in the presence of solvent. In terms of selectivity the addition of $\mathrm{Au}$ increase the selectivity to aldehyde from $62-68 \%$ for $\mathrm{Pd}$ based catalysts to $74-76 \%$ for Au-Pd based catalysts as also previously observed [10,23].

For PR24-PS based catalyst a dramatic increase of activity was observed using functionalized instead pristine CNTs. In fact the TOF increase from $7260 \mathrm{~h}^{-1}$ to $65876 \mathrm{~h}^{-1}$ for Pd based catalysts and from $9076 \mathrm{~h}^{-1}$ to $52638 \mathrm{~h}^{-1}$. However the functionalization appears not to affect the selectivity to benzaldehyde. The increasing of activity from pristine to functionalized CNTs can be address to the smaller nanoparticles and better dispersion present of $\mathrm{N}$ PR24.

On the contrary the effect of the $\mathrm{N}$-functionalization for Baytubes-based catalysts is not so important. Baytubes catalysts showed a better activity than PR24-PS but when $\mathrm{N}$-modified, the effect was small (TOF of $43281 \mathrm{~h}-1$ and 50387 h-1 for Pd/Baytubes and Pd/N-Baytubes and 33580 h-1 and 43479 for Au-Pd/Baytubes and Au-Pd/NBaytubes).

With respect to Activated carbon, nitrogen functionalized CNTs based catalysts showed a better activity whereas pristine CNTs are less active. This increasing of activity can be addressed to the increasing of metal dispersion being correlated to the introduction of $\mathrm{N}$ functionalities.

When water was used as the solvent $\left(0.3 \mathrm{M}, 60^{\circ} \mathrm{C}\right.$, alcohol/metal 1/500 and $1.5 \mathrm{atmO}_{2}$ ), the activities decreased as expected. Under such conditions we also tested cinnamyl alcohol as the reactant. As already observed [23] the addition of $\mathrm{Au}$ to Pd had a positive effect not only on the selectivity but also on the activity of the catalysts (table 3). As in the previous case the Baytubes-catalysts appeared more active than PR24-PS-ones and the effect of $\mathrm{N}$ functionalisation result in an important increasing of activity only in the case of PR24-PS. The same trend was observed in the case of cinnamyl alcohol, where the introduction of $\mathrm{N}$-funtionalities increased the activity of the catalyst without affecting the selectivity to aldehyde.

\section{Conclusion}

The synthesis of nitrogen doped carbon nanotubes has been achieved by oxidation with nitric acid and further amination with gaseous $\mathrm{NH}_{3}$. SEM revealed that this procedure is able to purify the surface of the CNTs from impurities like amorphous carbon, in particular on PR24-PS. The introduction of nitrogen functionalities on the surface of CNTs has a positive effect on the metal dispersion.

The functionalized N-CNTs based catalysts were tested in the selective oxidation of alcohols and compared to pristine CNTs based ones. Nitrogen functionalities incorporation led to a significant improvement of the catalytic performance. The activity improvement was attributed to a better dispersion of the metal nanoparticles on the surface. Moreover the increasing of the local basic environment did not affect the selectivity to aldehyde. 


\section{References}

[1] T.Mallat, A.Baiker, Chem.Rev. 104 (2004) 3037

[2] M. Besson, P. Gallezot, Catal .Taoday, 57 (2000) 127

[3] A. Sheldon, I.W.C.E. Arends, G.J. ten Brink, A. Dijksman, Acc. Chem. Res. 35 (2002) 774

[4] Sepulveda-Escribano, F. Colonna, F. Rodriguez-Reinoso, Appl. Catal. A.Gen., 173 (1998) 247

[5] Z. Liu, X. Lin, J. Y. Lee, W. Zhang, M. Han, L.M. Gan, Langmuir 18 (2002) 4054.

[6] Y. Xing, J. Phys Chem B. 108 (2004) 19255.

[7] H.-S. Kim, H. Lee, K.-S. Han, J.-H. Kim, M.-S. Song, M.-S. Park,J.-Y. Lee, J.-K. Kang, J.Phys.Chem. B 109 (2005), 8983.

[8] J.-Y. Lee, H. Lee, H.-S. Kim, Mater. Sci. Forum 475-479 (2005) 2463.

[9] Kong, M. G. Chapline, H. Dai, Adv. Mater. 13 (2001) 1384.

[10] A.Villa, D. Wang, N. Dimitratos, D. Su, V. Trevisan, L. Prati, Catal. Today (2009) doi:10.1016/j.cattod.2009.06.009.

[11] J.P. Tessonier, L. Pesant, G. Ehret, M.J. Ledoux, C. PhamHuu, Appl.Catal.A 288 (2005) 203.

[12] H. Vu, F. Goncalves, R. Philippe, E. Lamouroux, M. Corrias, Y. Kihn, D. Plee, P. Kalck, P. Serp, J. Catal. 240 (2006) 18.

[13] T. Matsumoto, T. Komatsu, H. Nakano, K. Arai, Y. Nagashima, T. Yoo, E.Yamazaki, M. Kijima, H. Shimizu, Y. Takasawa, J. Nakamura, Catal. Today, 90 (2004) 277.

[14] K. Balasubramanian, M. Burghard, Small, 1, (2005), 180.
[15] Jiang K.; Eitan A.; Schadler L. S.; Ajayan P. M.; Siegel R. W. Nano Lett. 3 (2003), 275.

[16] B.Choi, H. Yoon. I. Park, J. Jang, Y.Sung, Carbon, 45, (2007) 2496.

[17] Leprò X., Terries E., Vega-Cantù Y, Rodriguez-Macias F.J., Muramatsu H., Ahm Kim Y., Hayahsi T., Endo M., Torres R. M., Terrones M., Chem. Phys. Lett. 463 (2008), 124

[18] Amadou J.; Chirazi K.; Houllé M.; Janowska I.; Ersen O.; Bégin D. Pham-Huu C. Catal. Today 138, (2008), 62

[19] Yoon H.; Ko S.; Jang J. Chem. Commun. (2007), 1468

[20] R. Arrigo,M. Hävecker, R. Schlögl, D.S. Su, Chem. Comm., 2008, 4891

[21] J.P. Tessonnier, D. Rosenthal, T. W. Hansen, C. Hess, M. E. Schuster, R. Blume, F. Girgsdies, N. Pfaender, O. Timpe, D.S. Su, R. Schloegl, Carbon, 47, (2009), 1779.

[22] D. Wang, A. Villa, F. Porta, D. Su, L. Prati, Chemm. Commun. (2006) 1956.

[23] A. Villa, N. Janjic, P. Spontoni, D. Wang, D. S. Su, L. Prati, Appl. Catal., 364, (2009), 221.

[24] D.I. Enache, J.K. Edwards, P. Landon, B. Solsona-Espriu, A.F. Carley, A.A. Herzing, M. Watanabe, C.J. Kiely, D.W. Knight and G.J. Hutchings, Science 11 (2006) 362 